10 years ESJ

Special edition

\title{
Políticas lingüísticas in vivo e in vitro en el contexto de frontera
}

\author{
Maria Elena Pires-Santos, MA, PhD \\ Tatiane Lima de Paiva, MA \\ Ilídio Macaringue, MA, PhD \\ Universidade Estadual do Oeste do Paraná, Brazil
}

Doi: $10.19044 /$ esj.2021.v17n22p63

Submitted: 18 April 2020

Accepted: 18 June 2020

Published: 12 July 2021
Copyright 2021 Author(s)

Under Creative Commons BY-NC-ND

4.0 OPEN ACCESS

Cite As:

Pires-Santos, M. E.; Paiva, T. L.; Macaringue, I. (2021). Políticas lingüísticas in vivo e in vitro en el contexto de frontera. European Scientific Journal, ESJ, 17 (22), 63.

https://doi.org/10.19044/esj.2021.v17n22p63

\section{Resumen}

El objetivo de este artículo es comprender cómo las políticas lingüísticas "in vivo e in vitro" (Calvet, 2007; Oliveira e Altenhofen, 2011) se actualizan en el paisaje lingüístico de Ciudad del Este, más específicamente en el microcentro dirigido hacia el turismo de compras, en la región de libre comercio de la ciudad. Por tanto, tomamos en cuenta el principio defendido por Bourdieu (2008), según el cual no es el espacio que determina la lengua; por el contrario, es la lengua que define su espacio. Para tanto, adoptamos un estudio cualitativo/interpretativista, basándose en el escenario linguísticocultural de frontera Brasil/Paraguay, en este artículo interesa a nosotros comprender cómo las Políticas Lingüísticas in vivo e in vitro se actualizan en el paisaje lingüístico de Ciudad del Este, capturada por medio de fotografías. Los resultados del paisaje lingǘstico nos permitieron constatar que, en este contexto superdiverso de fronteras, las prácticas plurilingües y pluriculturales performatizan identidades que reposicionan las relaciones de poder subyacentes a las políticas lingüísticas in vitro ancladas en el estado-nación, engendrando políticas lingüísticas in vivo.

Keywords: Políticas Lingüísticas; Paisaje Lingüístico; Fronteras 


\section{Introducción}

En contexto de constitución de los Estados Nacionales, cada país adopta sus políticas lingüísticas ${ }^{1}$, como un complemento fundamental para el ejercicio de soberanía y de producción y reproducción de similitudes a partir de las cuales se debe pensar el país en el mundo, razón por la cual se busca la neutralización de las diversidades lingüísticas y culturales en el territorio del Estado, en el sentido de una nación, un pueblo, una lengua. En Paraguay, país que limita con Brasil y Argentina, por ejemplo, son oficiales las lenguas castellana y guaraní. Sin embargo, sobrepasando el control, hace parte de las prácticas discursivas, en aquel país, también el jopara, resultado del entrelazamiento del castellano y del guaraní y, aunque sea ampliamente utilizado en las prácticas de lenguaje cotidianos - como puede ser percibido en las prácticas de lenguaje de los trabajadores informales en las calles y en los periódicos locales de Ciudad del Este, ubicada en la Triple Frontera Brasil/Paraguay/Argentina, generalmente es visto como guaraní "equivocado" o castellano "equivocado".

Todavía pueden ser observadas en combinaciones en el espacio público, sean en las prácticas orales, en las fachadas de las tiendas, en los outdoors, en las calles, en folletos, etc., las lenguas portuguesa, china, coreana, árabe, entre otras lenguas, caracterizando de acuerdo con Shohamy y Gorter (2009) y Blommaert y Maly (2014) cuando denominan el hecho como "Paisaje Lingüístico". Esa configuración, resultante del mundo globalizado e interconectado, refleja la "superdiversidad", término acuñado por Vertovec (2007), para referirse a la 'diversificación de la diversidad' que, según el autor, es impulsada por la movilidad de personas alrededor del mundo, por la complejidad y por la imprevisibilidad contemporáneas.

La divergencia entre la invención de lenguas unificadas y homogeneizadas, vinculadas al estado/nación, de un lado, y las prácticas de lenguaje, de otro, ejemplifica aquello que Calvet (2007) caracteriza, respectivamente, como Política Lingüística in vitro y Política Lingüística in vivo. Aunque entendamos que la simplificación establecida por esa dicotomía no recobre las prácticas de lenguaje, principalmente en la frontera, esta perspectiva puede ayudarnos a comprender la complejidad de la frontera, sus prácticas de lenguaje y significados culturales. Así, comprendemos que las Políticas Lingüísticas no son tan solo desarrolladas por los Estados o por los órganos por sí delegados. Las personas socialmente instituidas pueden llevar a cabo de forma implícita o explícita acciones de políticas lingüísticas y, por

1 Este concepto - que será discutido más adelante - aunque considere la distinción entre política lingüística in vitro y política lingüística in vivo, por ser importante para las discusiones aquí propuestas, se emplea para "referir, tanto al establecimiento de objetivos (socio) lingüísticos, como a los modos de concretización de los mismos" (Maher, 2008, p. 411). 
esa vía, manifestar sus relaciones de poder las cuales, según Foucault (2001; 2004) son ejercidas y producidas en distintos contextos.

En ese escenario, debido a la potencia de las relaciones de fuerza y de poder que las lenguas y culturas llevan consigo, las Políticas Lingüísticas in vitro del Estado Paraguayo se han puesto en riesgo por las políticas in vivo, las cuales se apoderaron de Ciudad del Este, lo que nos permite reconfigurar nuestros posicionamientos sobre la diversidad lingüístico-cultural y nos "posibilita un modo de pensar el uso del lenguaje y de la identidad que evita categorías fundacionales" (Pennycook, 2006, p. 81), o sea, estas no derivan de la lógica de las ideologías dominantes de códigos fijos y delimitados e identidades unificadas. Del mismo modo como el lenguaje pasa a ser concebido como co-construido en las interacciones humanas como forma de realizar prácticas sociales (Fairclough, 2001), también las identidades no son pre-dadas, pero performadas en las prácticas discursivas (Pennycook, 2006; Moita Lopes, 2013) y, por eso, complejas, híbridas y mutables.

Considerando las configuraciones de lenguaje conectadas al Estadonación y aquellas realizadas en las interacciones habituales, en este artículo interesa a nosotros comprender cómo las Políticas Lingüísticas in vivo e in vitro se actualizan en el paisaje lingüístico de Ciudad del Este, a partir de imágenes fotográficas, más específicamente en el microcentro direccionado hacia el turismo de compras, en la región de libre comercio de la ciudad.

Así como las sociedades no son fijas e inmutables, los miembros de esta frontera tampoco lo son, pues como afirman Cuche (2002) y Canclini (2009), por medio de la cultura y del lenguaje los sujetos (des)construyen el cotidiano en sus prácticas discursivas y enmarcan las relaciones sociales. Defendiendo el lenguaje como una práctica social (conf. Fairclough, 2001), se implícita que lenguaje y sociedad son indisociables en la promoción de las políticas lingüísticas.

A partir de esas consideraciones iniciales - las cuales serán posteriormente ampliadas - para realizar el objetivo propuesto, este artículo se ancla en el área de Lingüística Aplicada que propone abordaje de prácticas situadas en contexto, en una perspectiva interdisciplinar (Cavalcanti, 2006; Moita lopes, 2006; Signorini, 2015), entre otros. Se orienta por un abordaje cualitativo/interpretativista cuya idea "consiste en un conjunto de prácticas materiales e interpretativas que dan visibilidad al mundo" (Denzin e Lincoln, 2006, p. 17).

Para tanto, este artículo está organizado en las siguientes secciones: además de la introducción, donde presentamos la panorámica general del trabajo, tenemos la primera sección, en la cual describimos el campo de investigación y caracterizamos el contexto de frontera donde se encuentran Ciudad del Este/Paraguay y Foz de Iguaçu/Brasil. En la segunda, traemos los 
fundamentos teóricos los cuales hacen el embasamiento del artículo y presentamos el análisis del paisaje lingüístico resultante de fotografías seleccionadas, en las cuales exploramos las prácticas de lenguaje resultadas de Políticas Lingüísticas in vivo e in vitro. Por último, en la conclusión, retomamos las líneas de la investigación que nos permitirán constatar cómo, en Ciudad del Este, se configuran las Políticas Linguiísticas del Estado y aquellas promovidas en las prácticas cotidianas.

\section{Fronteras: entre límites y movilidades}

Para tratar de las políticas lingüísticas actualizadas en el paisaje lingüístico de Ciudad del Este, se hace necesario, inicialmente, ubicar la Triple Frontera Brasil/Paraguay/Argentina, escenario en que hay una intensa movilidad de personas en todas las direcciones, sea motivada por el turismo o por otras razones, como el comercio, que se presenta diversificado en cada una de las ciudades fronterizas. El área comercial de cada uno de los tres países, aunque separados por el río Paraná y por las respectivas aduanas, se encuentran en un continuo urbano unido por el Puente de la Amistad (Brasil/Paraguay) y Puente de la Fraternidad (Brasil/Argentina). En la foto, a seguir, pueden ser observadas las ciudades fronterizas, Foz do Iguaçu/Brasil (margen derecha de la da foto) separada de Ciudad del Este/Paraguay (margen izquierda de la foto) por el río Paraná:

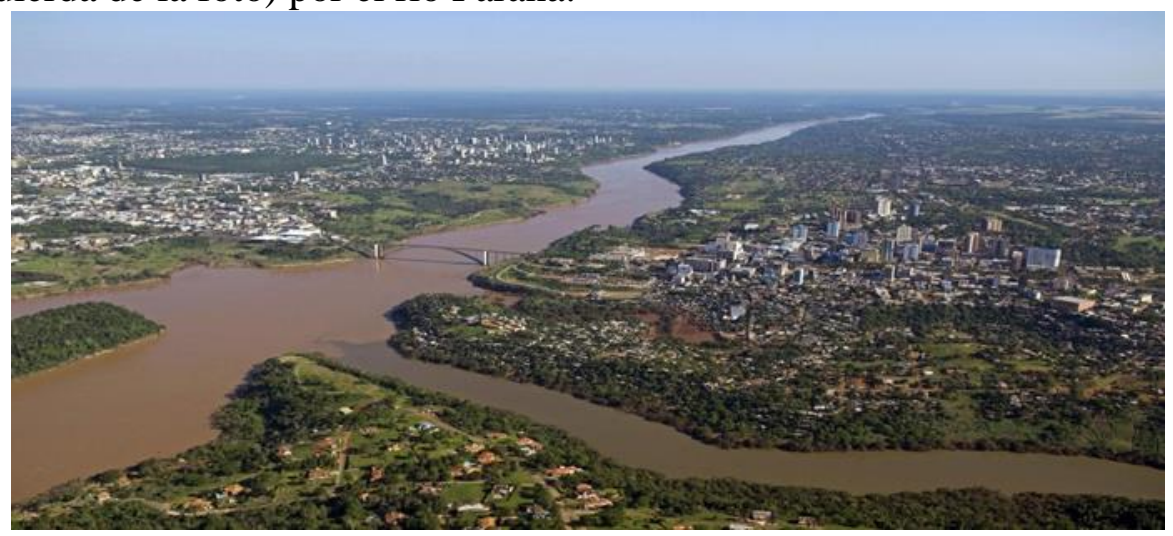

1 - Foto aérea de la Triple Frontera ${ }^{2}$

2 Foto adquirida de https://tyba.com.br/br/home/, acceso en 28/05/2019. cd213_504. Asunto: Vista aérea de de Ciudad del Este (derecha) Río Paraná, centro y Foz de Iguaçu al fondo Puente de la Amistad sobre el río Paraná / Local: Foz do Iguaçu - Paraná - PR; Ciudad del Este - Paraguay / Fecha: 11/2009 - Crédito: Delfim Martins / Tyba. 

LANGUAGE AND EDUCATION: THINKING (AND DOING) OTHERWISE

Foz do Iguaçu/Brasil, con 256.088 habitantes ${ }^{3}$; Puerto Iguazú/Argentina, con 80.020 habitantes $^{4}$; Ciudad del Este/Paraguay, con 387.538 habitantes $^{5}$ constituyen la Triple Frontera. Conjuntamente, la población de las tres ciudades suma alrededor de 600.000 habitantes. Además de esa población, la región recibe un contingente significativo de visitantes de todas las partes del mundo, atraído por el intenso comercio y por el importante polo turístico, principalmente las Cataratas del Iguazú, cañón por donde pasa el Río Iguazú y que, en 2016, solo del lado brasilero ${ }^{6}$, recibieron 1,5 millón ${ }^{7}$ de visitantes y también la Usina de Itaipu.

El área de comercio instalada en la Triple Frontera - principalmente en el libre comercio de Ciudad del Este - propicia la movilidad de personas en todas las direcciones, siendo comunes transportes colectivos los cuales cruzan los tres países, con la indicación "transporte urbano internacional". En Brasil, como en Paraguay y en Argentina, es recurrente la práctica de comercio en cuatro monedas: real/brasileña; guaraní/paraguaya; peso/argentina; dólar/americana. El tránsito de vehículos y personas es más intenso entre Brasil y Paraguay, eso hizo con que la comunidad reivindicara la construcción de más un puente para unir los dos países, cuya piedra fundamental fue lanzada en mayo de 2019. Bautizada como Puente Internacional de la Integración, será costeada con recursos de la Usina Hidroeléctrica de Itaipu, perteneciente a Brasil y a Paraguay y administrada por el Gobierno del Estado de Paraná.

Enfocando las fronteras aquí retratadas, Albuquerque (2010, p. 48) afirma que "las fronteras deben ser vistas como un campo singular de relaciones sociales entrelazadas con los actuales procesos de globalización y de redefinición de papel de los límites entre los Estados Nacionales" visto que, con la globalización, las fronteras se volvieron más híbridas, complejas y fluidas.

La Triple Frontera, al mismo tiempo en que es un espacio físico, en el cual transitan personas y bienes, es regida por normas legislativas específicas emanadas de los respectivos Estados, de tránsito o de acogimiento, también se

3 IBGE - Instituto Brasileiro de Geografia e Estatística. Censo 2010. Rio de Janeiro: IBGE. Disponible en https://www.ibge.gov.br/. Acceso en 15/02/2017.

4 Guíafe (2010) Disponible en

http://www.guiafe.com.ar/municipios/misiones/Puerto\%20Iguazu-poblacion.php. Acceso en 15/02/2017.

5 Municipalidad de Ciudad del Este (n.d.). Disponible en http://www.mcde.gov.py/vistas/historia.php. Acceso en 15/02/2017.

6 Localizadas en el Río Iguassu, que separa Brasil y Argentina, las Cataratas pueden ser visualizadas tanto del lado brasileño como del lado argentino, ambos constituyendo un importante polo turístico.

7 Disponible en http://www.brasil.gov.br/editoria/meio-ambiente/2017/02/parque-nacionaldo-iguacu-bateu-recorde-de-visitantes-em-janeiro, acceso en 15/02/2017. 
particulariza por ser simbólica por el hecho que las personas, aunque no sean las 'dueñas del territorio', una vez que este pertenece a los Estados Nacionales, ejercen acciones las cuales modifican sus vidas y vivencias en estos contextos, por medio de resignificaciones de los espacios delimitados. En tesis eso significa que tales espacios se tornan permeables y fluidos a causa de las relaciones que los pueblos establecen entre sí, casi que legislando sobre intereses recíprocos. Bajo la óptica de Rushdie (2007, p. 342) la frontera es "como una línea huidiza, visible e invisible, física y metafísica, amoral y moral". Así, si por un lado la frontera es pasible de fiscalización y punición en relación a aquellos que buscan la travesía, por otro es lugar de encuentros y diálogos, dando margen también a la transnacionalización, como ocurre en ese escenario de la Frontera Brasil/Paraguay/Argentina.

La región metropolitana de Ciudad del Este es la segunda más grande de Paraguay y abarca 4 municipios, a saber: Ciudad del Este, Hernandarias, Minga Guazú y Presidente Franco, totalizando un área de 1017 km². De estos, Ciudad del Este, nuestro escenario de investigación, cubre un área de $104 \mathrm{~km}^{2}$, ubicándose en el extremo este del país, al margen del río Paraná, alejándose 327 kilómetros de Asunción, capital del país. Ciudad del Este es la capital del departamento de Alto Paraná, se responsabiliza por la mitad del PIB (Producto Interior Bruto) del país. Dos polos mueven su economía: el agronegocio y el comercio. Cosmopolita, en ella viven y/o transitan personas de diferentes países y nacionalidades que buscan oportunidades de negocio, de empleo y de estudios, destacándose brasileños, árabes, chinos, coreanos.

Más allá del agronegocio y del comercio, el turismo desempeña un papel muy importante en el contexto de la diversidad lingüístico-cultural que caracteriza la ciudad. De las principales atracciones turísticas, enfatizamos los siguientes lugares: la represa de la Usina de Itaipu, una de las más grandes hidroeléctricas del mundo; los Saltos del Monday, caídas de agua del río de mismo nombre; el Monumento Científico Moisés Bertoni, un área protegida donde está la casa en la cual él realizaba sus investigaciones y publicaciones; el lago de la República, que es un espacio de recreación y está envuelto de vegetación; la Catedral de San Blas, que tiene el formato semejante a un barco y el Museo "El Mensú", ubicado en el edificio de la municipalidad.

Ciudad del Este es una de las ciudades más bulliciosa de Paraguay, debido a la intensa circulación de personas, bienes y mercancías, siendo considerada la tercera mayor zona de libre de comercio del mundo, razón por la cual practica precios relativamente bajos en relación a aquellos practicados en Brasil, debido al régimen fiscal y a la política de importaciones. Por su configuración, Ciudad del Este se torna un epicentro de convivio y de conflictos de culturas y lenguas, a las cuales están subyacentes relaciones de 
fuerza y de poder, evidenciados en las prácticas de lenguaje y sociales cotidianas, que se reflejan en el paisaje lingüístico local.

Considerando la complejidad de las líneas de frontera, para comprender el paisaje lingüístico de Ciudad del Este, se hace necesario también enfocar el camino recorrido de Foz do Iguaçu en dirección a aquella ciudad, pues en las fronteras unidas y, al mismo tiempo, separadas por el Puente de la Amistad, ya se encuentran, en tierras brasileñas, una profusión de letreros publicitarios anunciando las posibilidades de comercio en la ciudad vecina, como puede ser observado en las fotos que siguen:

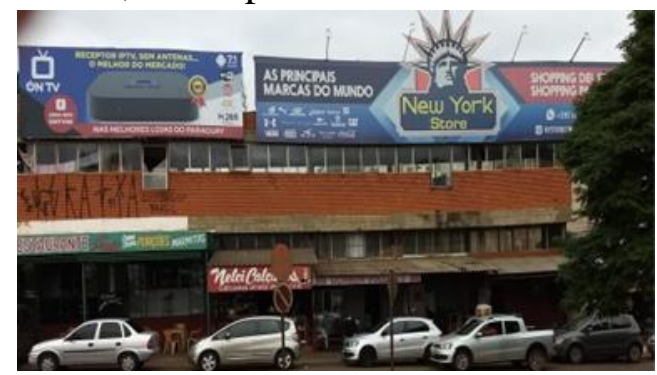

Foto 02 - Margen Derecha de BR 277

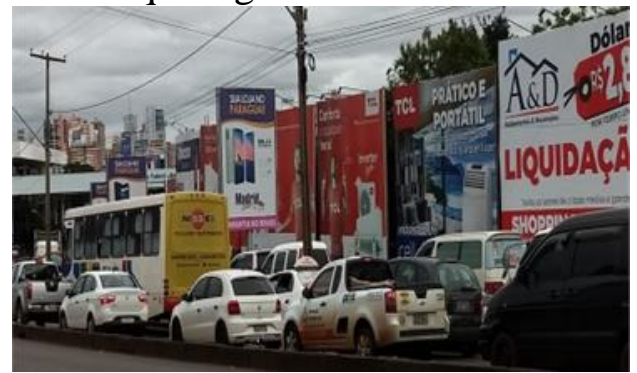

Foto 03 - Margen Izquierda de BR 277

Las dos fotos retratan la margen derecha y la margen izquierda de la BR 277, próxima a la aduana brasileña. Aunque los letreros publicitarios estén anunciando tiendas y productos del comercio de Ciudad del Este, la predominancia es de la lengua portuguesa, hecho que puede ser explicado porque están en territorio brasileño, indicando los probables interlocutores y ya buscando seducir los posibles compradores con la familiaridad de la lengua(je). Mismo siendo esta también la puerta de entrada para argentinos que viven en la Triple Frontera, la lengua castellana raramente se hace ahí presente, confirmando una interlocución principalmente con brasileños.

En el cantero central entre los carriles de la BR 277, se encuentra un único letrero publicitario escrito en varias lenguas (portuguesa, castellana, guaraní, inglesa, árabe) con expresión de bienvenidas, lo que amplía la referencia para diversos clientes, entre estas el castellano y el guaraní, anunciando una tienda de Ciudad del Este. 


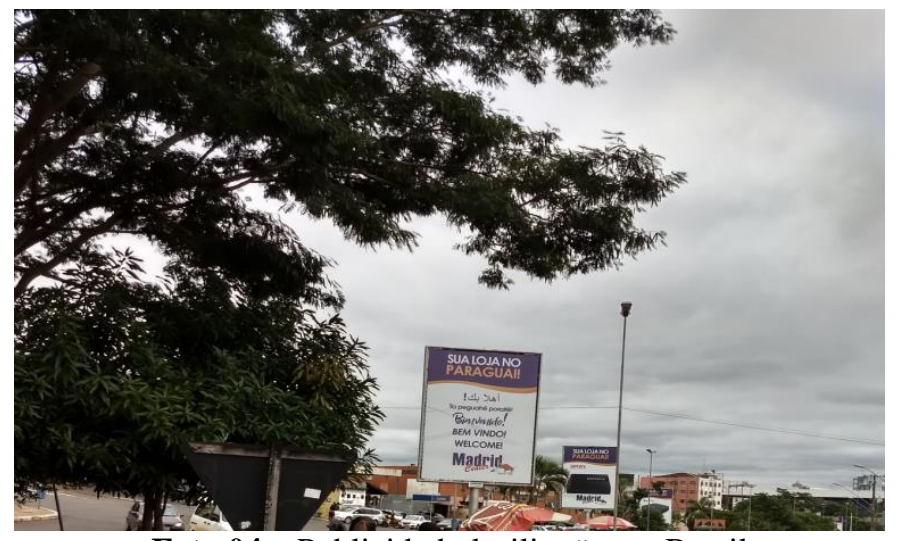

Foto 04 - Publicidad plurilingüe, en Brasil

La inclusión del castellano (Bienvenido!) y, en particular del guaraní (Ta peguahê paraitê!) - que raramente está presente en ese paisaje lingüístico - puede ser comprendida como una forma de refrendar la gente paraguaya, por medio del reconocimiento de las lenguas oficiales del país vecino dando la oportunidad a la comercialización de los productos de esta tienda, en su territorio.

Enaltecer la presencia de personas de más de 80 nacionalidades en la región es hecho común en las propagandas del sector de turismo. Así, la opción por dar visibilidad a varias lenguas puede ser entendida como una forma de acogimiento en relación a sus hablantes, pues como afirma Rushdie (2002, p. 359), "es hora, tal vez, de proponer una nueva tesis de la post-frontera: afirmar que la emergencia, en la era de la migración en masa, del desplazamiento en masa, de las finanzas e industrias globalizadas, de esta nueva, permeable postfrontera, es el trazo característico de nuestra época...".

Es pensando el sentido ambivalente de frontera, como líneas fijas y cambiantes, al mismo tiempo líneas que dividen espacios, personas, cosas, culturas y lengua(jes) y también lugar de oportunidades y encuentros, en que personas, lengua(jes) y culturas se entrelazan, que en la sección siguiente cruzamos/atravesamos las fronteras y adentramos tierras paraguayas, para dar secuencia al abordaje del paisaje lingüístico de Ciudad del Este, más específicamente de su región de libre comercio hacia el turismo de compras.

\section{Cruzando fronteras: entre Políticas Lingüísticas in vivo y Políticas Lingüísticas in vitro}

Según Calvet (2002, p. 145), Política Lingüística es "un conjunto de elecciones conscientes referentes a las relaciones entre lengua(s) y vida social, y planeamiento lingüístico [es] la implementación práctica de una política lingüística, en suma, el pasaje al acto". Teniendo en cuenta esta definición, se 
puede constatar que existe una relación jerárquica y organizacional entre Política Lingüística y Planeamiento Lingüístico, que equivale decir que el Planeamiento Lingüístico se subordina a la Política Lingüística, pues ella busca materializar las directrices que la política prescribe. Sin embargo, como no siempre estas directrices son seguidas, optamos por emplear Políticas Lingüísticas tanto para referirnos a las elecciones lingüísticas cuanto a su planeamiento, conforme propone Maher (2008).

Tradicionalmente vistas como acciones desarrolladas por el Estado para normalizar los usos de las lenguas, bien como establecer los respectivos estatutos en la sociedad, las políticas lingüísticas también pueden ser llevadas a cabo por personas organizadas para el efecto, no se constituyendo en acciones aisladas. En su forma oficial, son sistemáticas, estructuradas y estructurantes de determinadas situaciones lingüísticas y sociales y visan normatizar el "mercado lingüístico" (Bourdieu, 2008, p. 32) de las prácticas de lenguaje y establecer sus papeles en el contexto de ordenamiento del Estado-Nación y de la construcción de la identidad nacional está visto que, para el autor, "la lengua oficial está enredada con el Estado tanto en su génesis, como en sus usos. Es en el proceso de construcción del Estado que se crean las condiciones de constitución de un mercado lingüístico unificado y dominado por la lengua oficial".

Buscando legislar sobre las lenguas, en Paraguay, la Ley de Lenguas $4251^{8}$, sancionada por el Congreso de la Nación Paraguaya en 2013, establece:

Art. $1^{\circ}$. Objeto. La presente ley tiene por objeto establecer las modalidades de utilización de las lenguas oficiales de la República; disponer las medidas adecuadas para promover y garantizar el uso de las lenguas indígenas del Paraguay $\mathrm{y}$, asegurar el respeto de la comunicación visogestual o lengua de señas. A tal efecto, crea la estructura organizativa necesaria para el desarrollo de la política lingüística nacional (Paraguay, 2013).

Se hace importante observar que, aunque estén nominadas como oficiales las lenguas castellana y guaraní, la Ley de Lenguas hace referencia, en el plural, al "uso de las lenguas indígenas", evidenciando la necesidad de protección también de esas lenguas minoritarias no oficializadas y dejando implícito que, para la elevación del guaraní a la categoría de lengua oficial, otras lenguas indígenas han sido silenciadas. Hay, todavía, referencia a la "lengua de señas", aunque se busque asegurar apenas el respeto a su práctica. 
Sin embargo, no hay mención a otras lenguas que indudablemente hacen parte de las prácticas de lenguaje en aquel país, como las lenguas de migración como el alemán, el árabe, el mandarín, el tailandés, el francés, el portugués, el inglés (entre otras) y el jopara - lengua resultante del entrelazamiento entre el guaraní y el castellano - así denominada por los paraguayos los cuales la incluyen en sus interacciones.

Aunque pertenezca a las prácticas de lenguaje de los paraguayos, el jopara casi siempre es considerado por parte de la población como no siendo una lengua o constituyendo el "guaraní equivocado". Es común, cuando cuestionados sobre qué lengua hablan, responder que hablan el jopara y no el guaraní, pues perciben el distanciamiento entre sus prácticas de lenguaje y el guaraní normatizado que está en la gramática, en los libros y es enseñado en las escuelas.

El jopara puede ser oído en las prácticas orales de grande cantidad de pequeños comerciantes en sus puestos que bordean las calles más bulliciosas en frente a las grandes tiendas y centros comerciales, en las interacciones entre trabajadores informales y, también, en su forma escrita, en los periódicos populares. También dentro de las pequeñas tiendas es posible oír el guaraní y/o el jopara en las interacciones entre los empleados, pero su práctica no es percibida en las grandes tiendas de categoría internacional.

Es en este contexto que, cuando un Estado determina el estatuto de una lengua, tiene por objetivo la institucionalización de su estatuto jurídico, (conf. Oliveira y Altenhofen, 2011), eso le confiere todo un conjunto de proteccionismo del Estado y de sus segmentos de ejercicio del poder. Aun así, el estado no consigue impedir la diseminación de prácticas de lenguaje plurales en el contexto de las diferentes vertientes que reglamentan la vida de los ciudadanos, siendo que los sujetos pueden privilegiar/favorecer otras lenguas que no sean oficiales, como ocurre con el jopara y diversas lenguas de migración.

Al legislar sobre las lenguas, la Ley 4.251 establece las siguientes determinaciones que aquí interesa a nosotros más puntualmente para el abordaje del paisaje lingüístico de Ciudad del Este, por reglamentar las rotulaciones:

Art. $\mathbf{2 5}^{\circ}$. De las rotulaciones. Las gobernaciones y las municipalidades promulgarán reglamentaciones y velarán por su cumplimiento para que las rotulaciones de calles, señalizaciones, letreros comerciales, nominación de centros educacionales, culturales, recreativos, sociales, deportivos, religiosos y otros se expresen en ambas lenguas oficiales, una vez establecidos el alfabeto y la gramática oficial del idioma guaraní. En los territorios indígenas, se incluirán sus respectivas lenguas en las rotulaciones (PARAGUAY, 2013). 
Al considerar las políticas lingüísticas oficiales como aquellas que Calvet (2002) y Oliveira y Altenhofen (2011) denominan de in vitro, podemos ejemplificar con las fotos de las rotulaciones en ambientes oficiales, como aquellas que se encuentran en letreros y/o carteleras en la aduana, en las orientaciones espaciales como nombres de calles, avenidas, señalizaciones, etc., como ocurre en las fotos del centro comercial de Ciudad del Este:

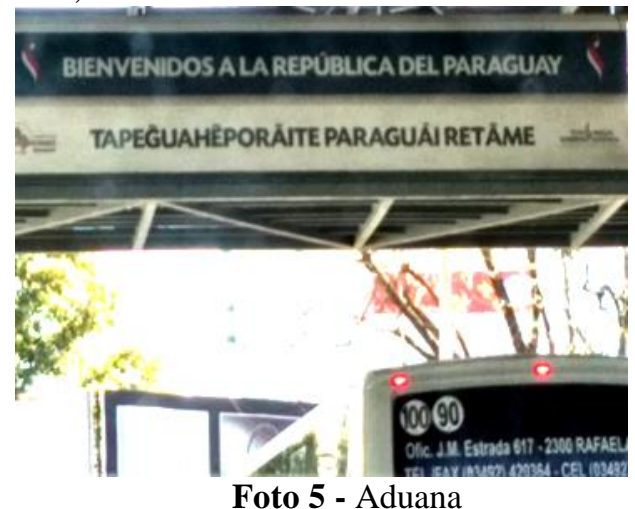

Foto 5 - Aduana

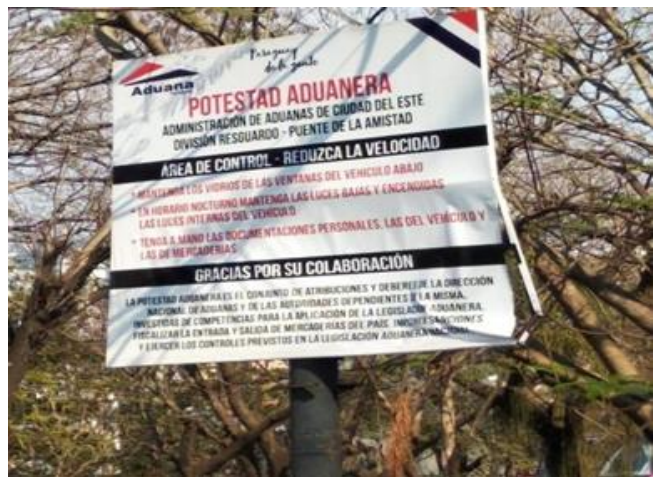

Foto 6 - Aduana

La foto 05 , la cual retrata el espacio de la aduana paraguaya trae, en la parte más alta de la estructura que recubre el local, un letrero de bienvenida, escrito en castellano y en guaraní, se percibe que está en conformidad con las políticas lingüísticas oficiales, o in vitro. Pero, todavía en ese espacio, la orientación para aquellos que entran en el país, como en la foto 06, se ve tan solo en castellano.

El paisaje lingüístico retrata que, aunque la Ley 4.251 establezca el uso de las dos lenguas oficiales, castellano y guaraní, esta última no siempre se ve presente en los contextos oficiales, siendo raramente encontrada también en el paisaje lingüístico del centro comercial de Ciudad del Este. Entre esos raros lugares, está el letrero abajo, (Foto 07), que se encuentra al lado derecho de la entrada de la ciudad, tras la aduana paraguaya, por donde entran los coches y los peatones y que tiene como finalidad dar las bienvenidas a los visitantes, reiterando el uso del guaraní como una lengua de la afectividad: 

LANGUAGE AND EDUCATION: THINKING (AND DOING) OTHERWISE

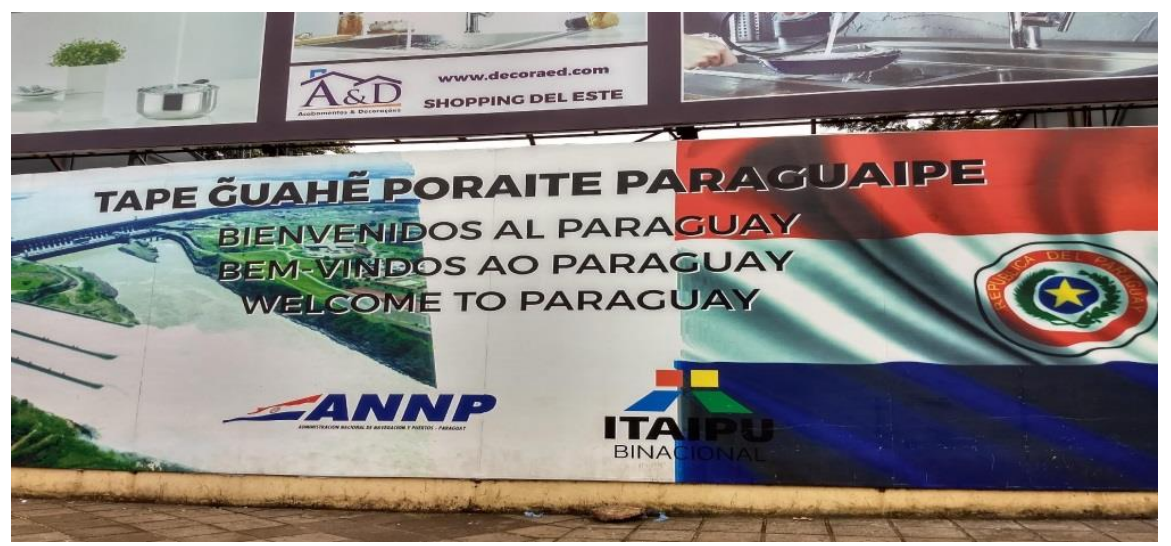

Foto 7 - Panel de bienvenidas

Este letrero, escrito en 04 lenguas (guaraní, castellano, portugués e inglés), destaca a la lengua guaraní, la cual aparece en primer lugar y en negrita, llenando un espacio más grande que las demás. Como pantalla de fondo, se encuentran los símbolos de la Usina Hidroeléctrica de Itaipu a un lado, enfocando la presa y el vertedero y, de otro, la bandera de Paraguay. En la parte de arriba del letrero, se encuentran anuncios publicitarios de tiendas, lo que refuerza la característica de la zona de libre comercio de la ciudad. Se observa la presencia de la lengua inglesa, remitiendo a su uso como una lengua franca, principalmente para el turismo, como también se puede observar en los letreros indicativos de lugares:

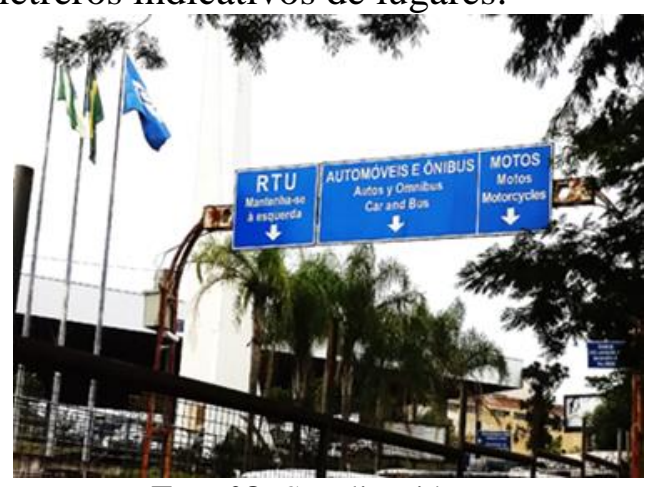

Foto 08- Señalización

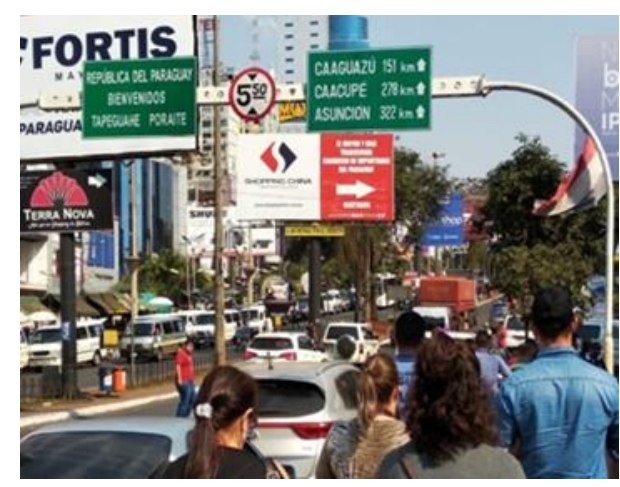

Foto 09- Señalización

En la fotografía 08, la señalización de la izquierda, indicativa de lugares, la escrita está en portugués - en primer plano y con letras mayúsculas - castellano (Autos y Ómnibus) e inglés (Car and Bus). El énfasis para la lengua portuguesa puede ser comprendida como indicativo del número significativo de brasileños que transitan por este espacio, tanto como compradores en el área de libre comercio, propietarios de tiendas y también 
sus empleados, bien como productores rurales que transitan de un país a otro, ya que esta frontera se caracteriza por el tránsito en ambas direcciones. Segundo investigación realizada por Prado (2017), en 2017 transitó por el Puente de la Amistad, entre Brasil y Paraguay, un promedio de 38.900 vehículos al día. Ese tránsito ocurre principalmente para el trabajo y para compras de electro electrónicos en el comercio de Ciudad del Este. La intensidad de ese tránsito motivó la construcción de otro puente para conectar los dos países, el cual le está subsidiando la Usina de Itaipu, con inicio en 2019.

En la imagen 09 los letreros, también indicativos de lugares, casi invisibles pese la profusión de propagandas comerciales, de un lado nombra el país (República del Paraguay) y da las bienvenidas al visitante en las dos lenguas, castellano (Bienvenidos) y guaraní (Tapeguahe Poraite). La otra indica la ruta para las ciudades de Caaguazu, Caacupe y Asunción.

Para Blomaert (2012) y Blomaert y Maly (2014), diferentemente de los espacios privados, los espacios públicos - como espacios normativos e instrumento de poder, disciplina y reglamenta - organizan la dinámica social. Sin embargo, esa normalización no es monolítica. Así, mismo que haya una ley la cual define las políticas lingüísticas, en la práctica se torna difícil polarizar el in vivo y el in vitro, pues las líneas que las apartan se diluyen, dando margen a configuraciones diferentes de aquellas oficialmente predeterminadas.

Continuando en el espacio público, pero pasando al comercio, nos deparamos con la imposibilidad de capturar en su totalidad la complejidad social, cultural y lingüística de la ciudad en un clik, dada el sinfín de tiendas, centros comerciales, puestos en las calles, vendedores ambulantes. Esta configuraçión local ocasiona una profusión de letreros, outdoors y carteles pintados en muros y fachadas para la indicación de las diferentes tiendas, centros comerciales y galerías, bien como anuncios de sus múltiples mercancías, principalmente electrónicos. Por entender tal limitación, traemos aquí algunas fotografías para ayudar en la captura del paisaje lingüístico local que, como argumenta Blommaert (2012), contribuye para la comprensión historicista de las características sociales y linguiísticas de un área. 


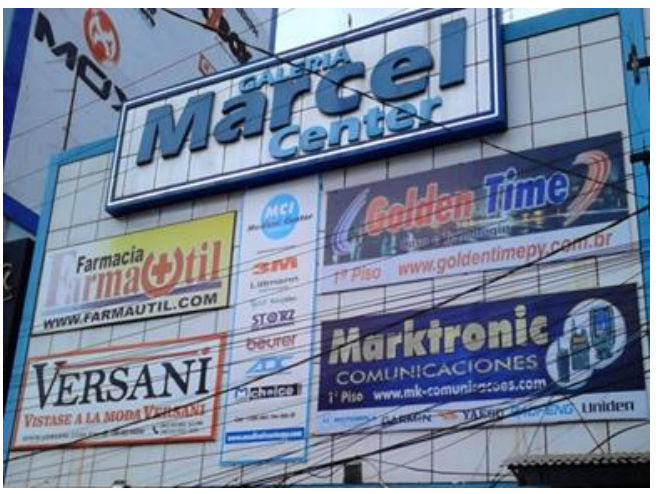

Foto 10-Cartelera

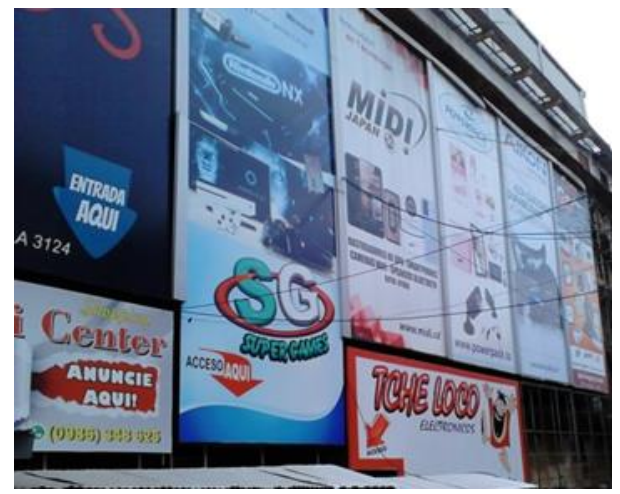

Foto 11-Cartelera

En las imágenes 10 y 11 predomina la lengua castellana (vístase a la moda Versani; comunicaciones; galería; Tche loco), si bien que algunas ocurrencias se confunden con la lengua portuguesa, pues son semejantes en las dos lenguas (entrada aqui; anuncie aqui). En castelhano, la ortografía seíia "entrada aquí/anuncie aquí".

Vale la pena comentar el uso de la expresión "Tche loco" para anunciar una tienda comercial. Del castellano, "che" corresponde a una interjección para establecer proximidad con el interlocutor. Pero, al mismo tiempo, remite a la expresión "Tche", de uso bastante común en la región Sur de Brasil evidenciando, una vez más, la dilución de las fronteras entre las diferentes lenguas.

La lengua inglesa como lengua franca se hace ahí presente, ratificando su empleo, no solo en Paraguay, en señalizaciones de lugares turísticos (Silva et al., 2017) y nombre de tiendas - como "Golden Time" - ejemplificado en el letrero. Aunque las políticas in vitro definan la obligatoriedad del castellano y del guaraní en ese escenario, una pluralidad de lenguas está ahí representada, contextualizando la pluralidad lingüística y cultural del escenario.

En la imagen12, la cual ilustra una tienda geminada dedicada al área de belleza y cuidados con el cuerpo, tenemos palabras escritas en español, árabe y aún parte de una palabra que está escrita en portugués "cabelereiro", estando fuera de las normas ortográficas de la lengua portuguesa, que establece la grafía "cabeleireiro".

Nos gustaría resaltar que, en función de las lenguas involucradas y por nuestras limitaciones en la representación gráfica, no podemos ilustrar las palabras en árabe ${ }^{9}$. La indicación del local, escrita en español (Salón de

9 Entendemos que el rótulo "lenguas árabes" es una simplificación que recubre una profusión de nacionalidades y lenguas. Sin embargo, optamos por tal empleo por la imposibilidad, en ese espacio, de especificaciones puntuales. 
Belleza) divide el protagonismo con otras escritas en árabe, conforme ilustran las imágenes abajo.

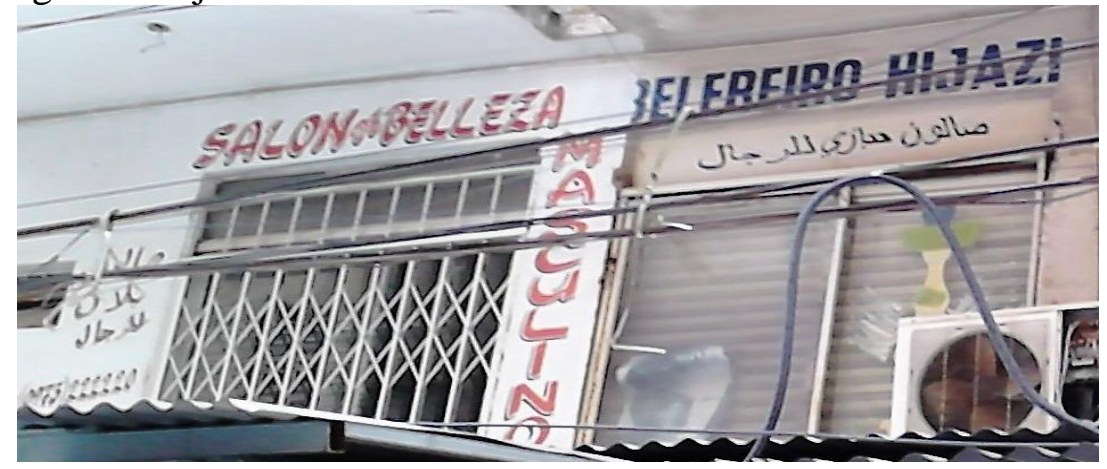

Foto 12 - Cartelera

Aunque en esa fachada se encuentren denominaciones en lenguas árabes, llama la atención - como residentes que vivencian la Triple Frontera la casi completa ausencia de las lenguas árabes y chinas en el paisaje lingüístico, aunque estos constituyan una gran cantidad de propietarios de tiendas en Ciudad del Este. Las lenguas árabes, en ese escenario, están más representadas por los nombres propios, como puede ser ejemplificado en esta publicidad: "CABELEREIRO HIJAZI".

Todavía en las áreas comerciales, la polaridad entre las nominaciones de las varias lenguas se vuelve aún más difusa, como puede ser observado en las fotos 13 y 14 a seguir, las cuales retratan la fachada de dos tiendas de utilidades, de entre muchas otras económicamente más populares, conocidas como autoservicio, para indicar la venta de productos de uso general, con precios bajos, como enunciado en el rodapié de la escalera, acceso a la tienda: "todo lo que su familia necesita". En Foz do Iguaçu, es común la gente denominar tiendas semejantes como autoservicio ${ }^{10}$, evidenciando la influencia del castellano en esa denominación.

10 En Brasil, esas tiendas son más comúnmente reconocidas como R\$ 1,99, para hacer referencia al bajo costo de las mercancías. 

LANGUAGE AND EDUCATION: THINKING (AND DOING) OTHERWISE

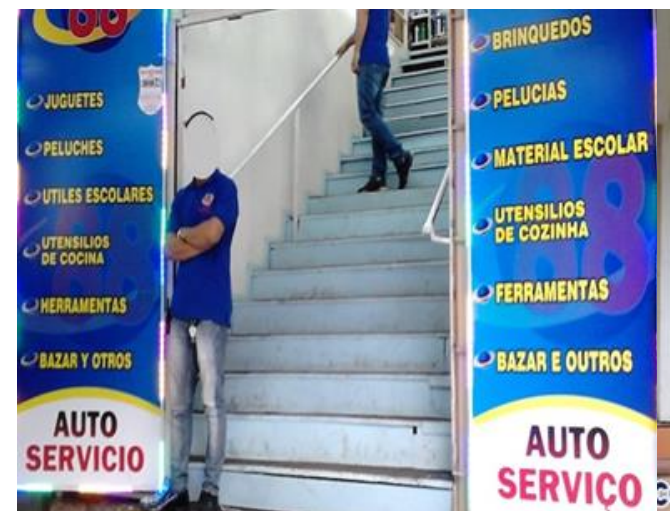

Foto 13- Ubicación de la tienda

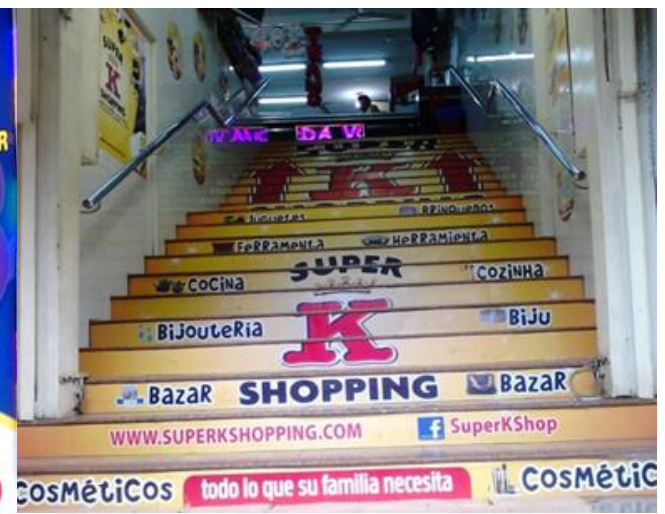

Foto 14 -Ubicación de la tienda

En las dos fotos, capturamos las imágenes externas a los ambientes de compras, pues entendemos que ellas permiten establecer el primer contacto de los compradores con las tiendas. Son también referencias de localización, ya que la cantidad de establecimientos de autoservicio es grande y su identificación externa es una de las garantías de llegada del comprador hasta el local, siendo casi todas localizadas en el mismo espacio de la ciudad, próximas unas a las otras, al lado izquierdo de la Ruta Dr. José Gaspar Rodríguez de Francia.

En la foto 13, la opción fue por la traducción: de un lado, castellano (juguetes, peluches, útiles escolares, herramientas, bazar y otros); de otro, portugués (brinquedos, pelúcias, material escolar, utensílios de cozinha, ferramentas, bazar e outros). En la foto 14, hay un juego de palabras diferenciadas tanto por la grafía como fonéticamente, siendo escritas en la escalera, en una alternancia entre portugués y castellano: bazar/bazar; bijouteria/biju; cocina/cozinha; herramienta/ferramenta).

Con eso, se presupone la inteligibilidad portugués/español y se facilita la recepción de las informaciones por quienes las reciben, este hecho nos permite entender que los usos de las lenguas son legitimados por los contextos y por intereses inherentes al posicionamiento de los practicantes, en sus prácticas discursivas.

La imagen 15, a seguir, ilustra el apelo al consumo representado por el ícono de la belleza, que es la imagen de la mujer exuberante, acompañada de palabras en castellano, de efecto tales como belleza y calidad de vida, para significar, metafóricamente, que la marca del producto es sinónimo de calidad de vida y de belleza: 


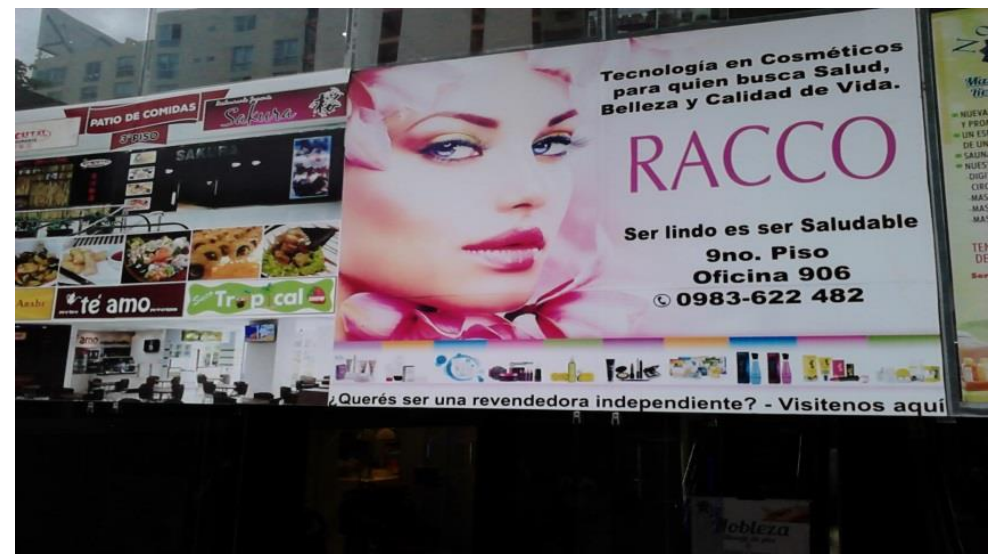

Foto 15 - Cartelera

Otro aspecto que nos llamó la atención es que en algunas tiendas de venta de productos de belleza o de tratamiento del cuerpo, se recurre mucho al español, un posicionamiento que nos lleva a considerar que el alcance del tipo de consumidores está identificado, esto es, hay una preocupación especial con el mercado de consumo paraguayo, posiblemente porque los mercados competidores, sobre todo del lado brasileño, ya están consagrados y estabilizados en términos de confianza de los consumidores en determinadas marcas. Además, la explicación en el pie de página del cartel aclara su finalidad, que es atraer vendedoras para el producto, preferentemente paraguayas: "¿Querés ser una revendedora independiente? - Visítenos aquí".

Haciendo parte del mismo letrero, varias otras publicidades son puestas, como se puede observar por el juego de palabras que atrae la atención para una casa de té oriental: "té amo". Señalada con letras minúsculas, la expresión "te amo" remite a la frase común en portugués, para declarar sentimientos por alguien. En castellano, la grafía es, básicamente, la misma, salvo por el uso del acento diacrítico. Sin embargo, en castellano, té significa "chá". Como nombre de una tienda, puede ser comprendido también de la siguiente forma: "amo chá". La alternancia entre la lengua portuguesa y el castellano puede todavía ser observada en las diferentes denominaciones del cartel: en castellano (patio de comidas/praça de alimentação); en portugués (Suco Tropical/Jugo Tropical).

García (2009, p. 9) señala que las lenguas no están simplemente en contacto, pues "la complejidad del mundo moderno incluye situaciones en que dos o más lenguas son usadas en combinaciones también bastante complejas", a que la autora denomina translenguaje, para explicar el flujo del hibridismo de culturas y de lenguas que, por el movimiento de personas alrededor del globo y por el uso de tecnologías, se volvió la norma. 
Las fotos 16 y 17 fueron sacadas de las fachadas de un Mercado de productos orientales y un restaurante que sirve alimento oriental; la 18, fue fotografiada en el interior de un restaurante self service, cuyos propietarios son brasileños y sirven comida brasileña y árabe.

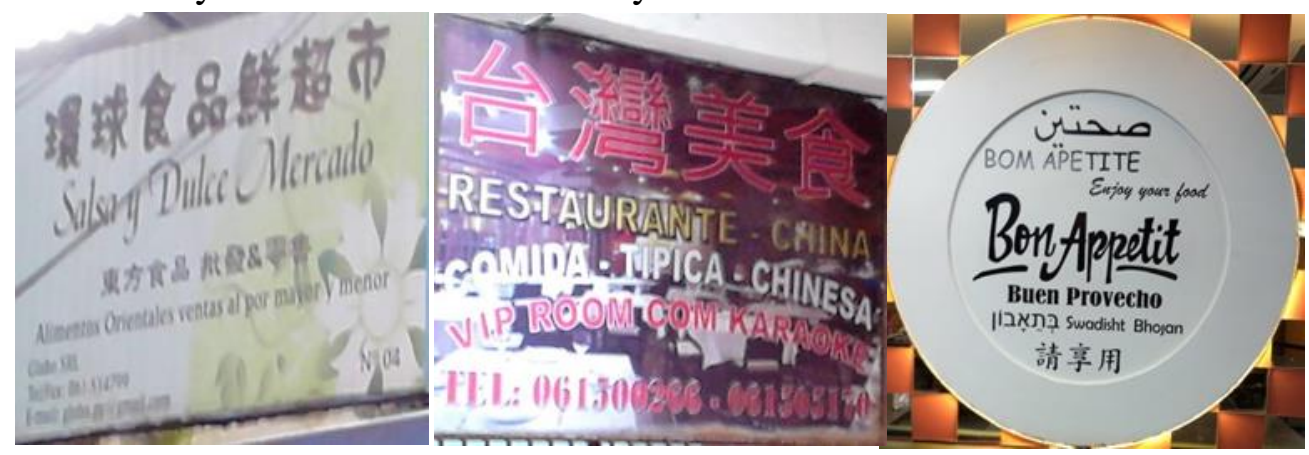

Foto 16 - restaurante

Foto 17- Restaurante

Foto 18- decoración

Vemos, en esas fotografías, el entrelazamiento de varias lenguas. En la foto 16, las lenguas chinas ${ }^{11}$ dividen espacio con el castellano (Salsa y Dulce Mercado/Alimentos orientales ventas al por mayor y menor). Es interesante observar el empleo de "alimentos" (portugués) por "comida" (castellano).

En la foto 17, las lenguas chinas dividen espacio con el portugués (Restaurante China/comida típica china) y el inglés (VIP ROOM COM KARAOKÊ: VIP - sigla que significa "Very Important Person"/Room - sala). Es interesante observar que la expresión en inglés VIP ROOM, ya consagrada en Brasil para indicar un local para personas consideradas importantes, es seguida de la preposición en portugués "COM", para introducir la expresión Karaoke, de origen oriental, más popularizada en Brasil con el mismo significado. Aunque hagamos esa segmentación nombrando diferentes lenguas, el enunciado sólo puede ser comprendido cuando contextualizado en la frontera, para indicar la creatividad de las prácticas translengues en la construcción de sentidos del mundo, según argumenta García (2009).

La foto 18 ejemplifica, con su referencia a la pluralidad lingüística de los posibles clientes provenientes de diversos y longincuos países, la movilidad de personas alrededor del mundo caracterizada por la superdiversidad (Vertovec, 2006), la cual, también para Bloomaert (2014, p. 11) es guiada por tres características, como se verificó en el paisaje lingüístico aquí abordado: movilidad, complejidad e imprevisibilidad.

11 Del mismo modo que hicimos para las "lenguas árabes", optamos por la denominación generalizada "lenguas chinas", para que hubiese riesgo de inadecuaciones. 
Dejando el área comercial de Ciudad del Este y cruzando la frontera de regreso a Brasil nos deparamos, en la pasarela que da acceso a la aduana brasileña, con las frases a seguir, en las tres lenguas: guaraní, portugués y castellano. Como están escritas en la pared/muro de protección que circunda las vías de acceso a la aduana del lado del Río Paraná, teniendo del otro lado las telas que separan esa vía de aquella utilizada por los coches, traemos aquí un montaje, por la imposibilidad de registrarlos en la totalidad, pues estas no están sobrepuestas, como aquí presentadas, pero distribuidas a lo largo de la vía, ocupando un largo espacio:

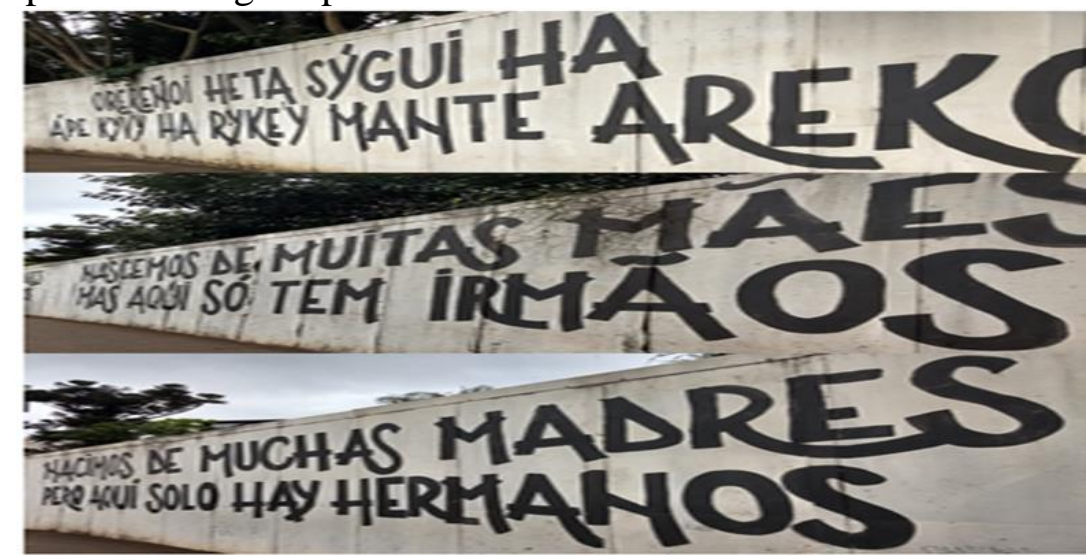

Foto 19 - Panel

Ese letrero, firmado por la Fundación Cultural de Foz do Iguaçu es intitulado Acción Poética Tres Fronteras, presenta los mismos dichos en guaraní, portugués y castellano, en la siguiente orden: OREREÑOI HETA SÝGUI HÁ / ÂPE KYVY HA RYKE'Y MANTE AREKO; NASCEMOS DE MUITAS MÃES / MAS AQUI SÓ HÁ IRMÃOS; NACIMOS DE MUCHAS MADRES / PERO AQUÍ SOLO HAY HERMANOS.

Enaltecer las relaciones armoniosas hace parte de las prácticas sociales, culturales y económicas de la frontera, región de encuentros, pero también de conflictos. En este sentido, en cuanto los Estados preconizan sus políticas lingüísticas y las estrategias de prácticas de lenguaje en el contexto de superdiversidad a partir de la demarcación de las fronteras geográficas, se deja presuponer que, al cruzar una frontera para el otro país, se modifican los lenguajes. Pero, en la práctica, tal ni siempre ocurre, pues las personas socialmente constituidas en contextos específicos es que determinan las prácticas de lenguaje con las cuales pretenden actuar en el mundo.

Enfocar el paisaje lingüístico de un escenario, entonces, puede ayudarnos a comprender las relaciones de fuerza, o centrípetas, o centrífugas que traspasan las prácticas de lenguaje. Como argumenta Blommaert (2012), 
los paisajes lingüísticos, que pueden ser captados por los equipamientos de sonido e imagen, se volvieron potenciales para la percepción de partes visibles de las prácticas de lenguaje, evidenciando la semiosis de espacios extremadamente multilingüies y multiculturales en que se sobreponen capas sobre capas de complejidades no unificadas en la vida social, en la actualidad.

Podemos decir que la política lingüística in vivo consagra la pluralidad lingüística y cultural, lo que remite a performances identitarias (Pennycook, 2006) que rompen con las fronteras lingüísticas y simbólicas (un pueblo, una lengua), evidenciando identidades complejas, provisorias, construidas basándose en ideologías e intereses los cuales conectan mercado lingüístico y mercado económico. A este propósito, Pires-Santos (2004, p. 70) enfatiza que "de la misma forma, si no hay lugar para la noción de identidad centrada, unificada, tampoco hay lugar para el lenguaje en cuanto sistema homogéneo, pero en desequilibrio, siempre heterogéneo y complejo", a ejemplo de la configuración social de Ciudad del Este ha pasado por metamorfosis decurrentes del amplio proceso migratorio y tránsito elevado de personas, lo que impacta los flujos sociales, sociolingüísticos y culturales.

Con eso, Ciudad del Este se consagra como un espacio cosmopolita en el cual son edificadas y resignificadas las relaciones sociales, culturales y económicas por medio de las prácticas de lenguaje reflejadas en su paisaje lingüístico, convirtiéndose un lugar por excelencia para hacer emerger la riqueza lingüística y cultural la cual resulta de su mosaico y que no se encaja en el primado de las políticas lingüísticas determinadas por el Estado, o sea, in vitro. Por consiguiente, las políticas lingüísticas in vitro son subvertidas por las políticas lingüísticas in vivo, exponiendo que los sujetos, con sus prácticas de lenguaje, también interfieren en su efectividad.

\section{Conclusión}

Buscamos comprender, en este artículo, como las políticas lingüísticas in vivo e in vitro se actualizan en el paisaje lingüístico de Ciudad del Este, más específicamente en la región de libre comercio de la ciudad.

De los análisis hechos, percibimos que así como este medio macrosocial (triple frontera) se vuelve único por su localización, por la composición territorial fronteriza, por los puntos turísticos y por el intenso comercio nos permite percibir que, cualquier que sea la política lingüística del Estado-Nación, jamás será unánime porque ella emana de un problema legítimo o legitimado al mismo tiempo por la sociedad y por el poder estatal. Este último no lleva en cuenta, en sus fundamentos político-ideológicos, que la pretensa fabricación de las semejanzas no implica copia en carbono del otro porque las lenguas, como las culturas e identidades son dinámicas y, como tal, los sujetos no son meros e ilustres pasivos en las prácticas socioculturales y 
lingüísticas de las cuales hacen parte. Al revés, dinamizan y reconfiguran las prácticas de lenguaje de las cuales participan.

Así, el paisaje lingüístico retoca la idea de frontera, al mismo tiempo como línea que divide espacio, personas, cosas, culturas y lenguaje, bien como espacio de oportunidades, encuentros y diálogos en que personas, lenguajes y culturas están entrelazadas. Así, las prácticas plurilingües y pluriculturales performatizan identidades que reposicionan las relaciones de poder subyacentes a las políticas lingüísticas in vitro ancoradas en el Estado-Nación, engendrando políticas lingüísticas in vivo.

\section{References:}

1. Albuquerque, J. L. C. (2010) A dinâmica das fronteiras: os brasiguaios na fronteira entre o Brasil e o Paraguai. Annablume.

2. Blommaert, J. (2012) Chronicles of complexity: ethnography, superdiversity and linguistic landscapes. Tilburg Papers in Culture Studies. Tilburg University.

3. Blommaert, J. e Maly, I. (2014) Ethnographic linguistic landscape analysis and social change: a case study. Tilburg Papers in Culture Studies. Tilburg University.

4. Bourdieu, P. (2008) A economia das trocas linguísticas. Editora da Universidade de São Paulo.

5. Calvet, L.-J. (2007) As Políticas Linguísticas. IPOL/Parábola.

6. Calvet, L-J. (2002) Sociolinguística: uma introdução crítica. Parábola Editorial.

7. Canclini, N. G. (2009) Diferentes, desiguais e desconectados. Editora UFRJ.

8. Cavalcanti, M. C. (2006) Um olhar metateórico e metametodológico em pesquisa em Linguística Aplicada: implicações éticas e políticas. In: L. P. Moita Lopes (Org.). Por uma linguística aplicada indisciplinar (pp. 233-252). Parábola Editorial.

9. Cuche, D. (2002) A noção de cultura nas ciências sociais. EDUCS.

10. Denzin, N. K.; Lincoln, Y. S. (2006) O sétimo momento: deixando o passado para trás. In: N. K Denzin; Y. S. Lincoln (Orgs.). $O$ planejamento da pesquisa qualitativa: teorias e abordagens (pp. 389405). Artmed.

11. Fairclough, N. (2001) Discurso e mudança social. UnB.

12. Focault, M. (2004) Microfisica do poder. Graal.

13. Focault, M. (2001) História da sexualidade: a vontade de saber. Graal.

14. Garcia, O. (2009) Bilinguism and Education. In: O. Garcia (Org.) Bilingual Educationin the 21st. Century - a global perspective. WileyBlackwell. 
15. Maher, T. M. (2008) Em busca do conforto linguístico e metodológico no Acre indígena. Trabalhos em Linguística Aplicada, p. 233-252. Campinas, 47 (2), jul./dez.

16. Moita Lopes, L.P. (2006) Linguística aplicada e vida contemporânea: problematização dos construtos que têm orientado a pesquisa. In: L P. Moita Lopes (Org.) Por uma linguística aplicada indisciplinar (pp. 85107) Parábola Editorial.

17. Moita Lopes, L. P. (2013) Gênero, sexualidade, raça em contextos de letramentos escolares. In: L.P. Moita Lopes (Org.) Linguística Aplicada na modernidade recente (pp. 227-248). Parábola.

18. Oliveira, G. M.; Altenhofen, C. (2011) O in vitro e o in vivo na política da diversidade linguística no Brasil: inserção e exclusão do plurilinguismo na educação e na sociedade. In: H. Mello; C. Altenhofen; T. Raso. (Orgs.). Os contatos linguísticos no Brasil (pp. 13-56). Editora UFMG.

19. Pennycook, A.(2006) Uma linguística aplicada transgressiva. In: L. P. Moita Lopes (Org.). Por uma linguística aplicada indisciplinar (pp. 67-84). Parábola Editorial.

20. Pires-Santos, M. E. (2004) O cenário multilingue/multidialetal/multicultural de fronteira e o processo identitário "brasiguaio" na escola e no entorno social. Tese de doutorado. Campinas: IEL, Unicamp.

21. Prado, F. H. (2017) Pesquisa sobre o tráfego de veículos e pessoas que atravessam a Ponte Intrnacional da Amizade. Foz do Iguaçu: Centro Universitário Dinâmica das Cataratas. Disponível em http://www.udc.edu.br/libwww/resources/revista/Pesquisa-VeiculosPy-2018/index.html, acesso em 12/02/2019.

22. Rushdie, S. (2002) Cruze esta linha. Ensaios e artigos. Cia das Letras.

23. Signorini, I. (2013) Bordas e Fronteiras entre escritas grafocêntricas e hipermidiáticas. In: L.P. Moita Lopes (Org.) Linguística Aplicada na modernidade recente (pp. 227-248). Parábola.

24. Shohamy, E.; Gorter, D. (2009) Linguistic landscape: expanding the scenary. New York: Routledge.

25. Silva, I.; Pires-Santos, M. E.; Jung, N. M. (2017) Multilinguismo e política linguística: análise de uma paisagem linguística transfronteiriça. Domínios da Lingu@ gem, p. 1258-1277. Uberlândia. Vol. N. 4, out./dez.

26. Vertovec, S. (2007) Super-diversity and its implications. Ethnic and Racial Studies, p. 1024-1054. Vol. 30, no.6, November. 